\title{
Microstructure Evolution of Low Carbon Steel via Flash Processing
}

Qianying Guo ${ }^{1}$, Thomas R. Watkins ${ }^{1}$, Artem Trofimov ${ }^{1}$, Hsin Wang ${ }^{1}$, Gary Cola ${ }^{2}$, Thomas R. Muth ${ }^{1}$, Dileep Singh ${ }^{3}$, Jonova Thomas ${ }^{3}$, Sudarsanam Babu ${ }^{4}$ and Kinga A. Unocic ${ }^{1}$

${ }^{1}$ Center for Nanophase Materials Sciences, Oak Ridge National Laboratory, United States, ${ }^{2}$ Flash Steelworks, Inc, United States, ${ }^{3}$ Argonne National Laboratory, United States, ${ }^{4}$ UT-Battelle LLC, Oak Ridge, Tennessee, United States

Low carbon steel is widely used in many industrial products including steel framing, semi-finished (flat, square, or round) bars, machinery parts, etc., due to its low cost and good ductility [1]. However, as expected, its mechanical properties, especially the yield and tensile strength, are relatively low when compared to high-strength steels. Improving mechanical properties of these steels while retaining sufficient ductility to maintain good formability is an important research topic over the past decade with studies mainly focusing on innovative mechanical processing techniques that involve severe plastic deformation. A relatively new thermal processing technique known as "flash processing" was developed to produce resilient steel plates/sheet with improved strength while retaining some ductility using commercial low carbon steel [2]. By incorporating rapid heating and rapid cooling, the flash process generates heterogeneous microstructures throughout the coil's thickness, resulting in hardness variations.

In this study, a commercial AISI 1020 low carbon steel (Fe-0.21C-1.03Mn-0.3Si-0.06Al-0.04Cr-0.03Cu $0.01 \mathrm{~N}-0.01 \mathrm{Mo}-0.01 \mathrm{Ni}-0.014 \mathrm{P}-0.002 \mathrm{~S}$ wt. $\%$ ) coil was used with an initial thickness $\sim 1.14 \mathrm{~mm}$. The flash process was performed using a custom-built machine. The machine was equipped with top rollers to guide the sheets into the induction coil, wherein the sheets were rapidly heated. After passing through the induction coil, the sheets continued into a quenching bath. Flash temperature was selected at $1125^{\circ} \mathrm{C}$. The quenching bath was positioned below the induction coils with water jets within the bath that impinging water onto the steel sheets on both sides.

Detailed microstructural characterization of both as-received and after flash process conditions were conducted at different length scales using scanning electron microscopy - electron backscatter diffraction (SEM-EBSD) analysis (Tescan MIRA3 SEM) and scanning transmission electron microscopy (STEM). EBSD orientation maps were collected at $15 \mathrm{kV}$ with a beam intensity of $9.7 \mathrm{nA}$ at $1000 \mathrm{x}$ with the step size of $0.8 \mu \mathrm{m}$. STEM analysis was performed using FEI F200X Talos operating at $200 \mathrm{kV}$ equipped with high-angle annular dark-field (HAADF) detector and Super-X energy dispersive X-ray spectroscopy (EDS) system with 4 silicon-drift detectors. An aberration-corrected JEOL 2200FS STEM/TEM instrument operated at $200 \mathrm{kV}$ was also used to study microstructure at the atomic level. TEM specimens were prepared via focused ion beam (FIB) in situ lift-out techniques using a Hitachi NB5000 FIB-SEM.

The as-received 1020 steel had equiaxed grains (Fig. 1a). After flash process at $1125^{\circ} \mathrm{C}$, the equiaxed grain morphology disappeared, and a high density of martensitic/bainitic lath structures were revealed (Fig. 1b). Also, residual ferrite grains were found, which was confirmed by both selected area electron diffraction analysis and x-ray diffraction analysis (not shown here). Furthermore, within the ferrite grains, very small $(15-25 \mathrm{~nm})$ lath structures were noted, as shown in Figure 2a. High magnification STEM-EDS analysis indicated higher concentration levels of carbon associated with these nanosized laths, suggesting presence of a carbide phase (Fig. 2b). Further, high-resolution STEM was performed at 
the nanosized carbide region/ferrite matrix regions (Fig. 2c). Fast Fourier Transform (FFT) analysis of the marked region in the carbide was used and Figure $2 \mathrm{~d}$ shows an indexed FFT pattern. Based on interplanar spacing and angle measurements, these nanosized carbides were identified as the orthorhombic $\mathrm{Fe}_{3} \mathrm{C}$ phase [3]. This phase usually forms within $\alpha$-ferrite due to low carbon solubility $(0.022 \mathrm{wt} . \%)$. The current study indicates that flash processing is a promising technique to process low carbon steels to improve their mechanical properties by introducing heterogeneous microstructures [4].

(a)

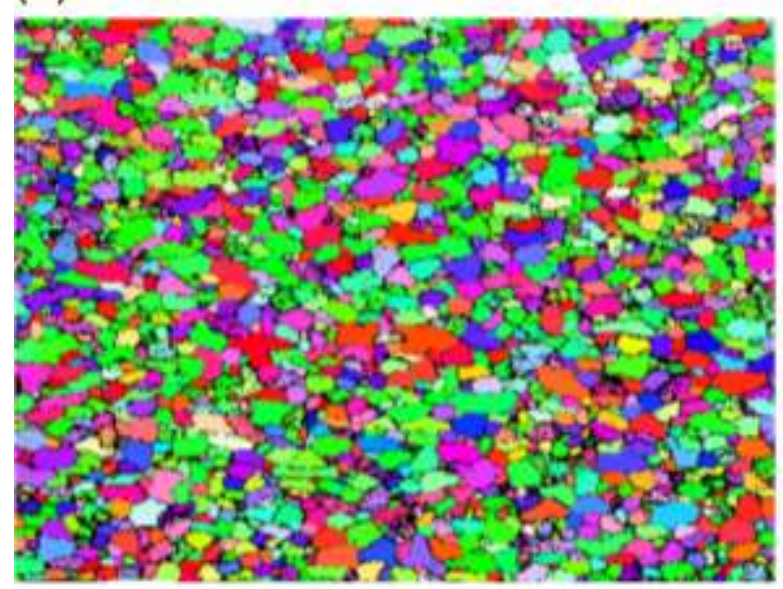

(c)

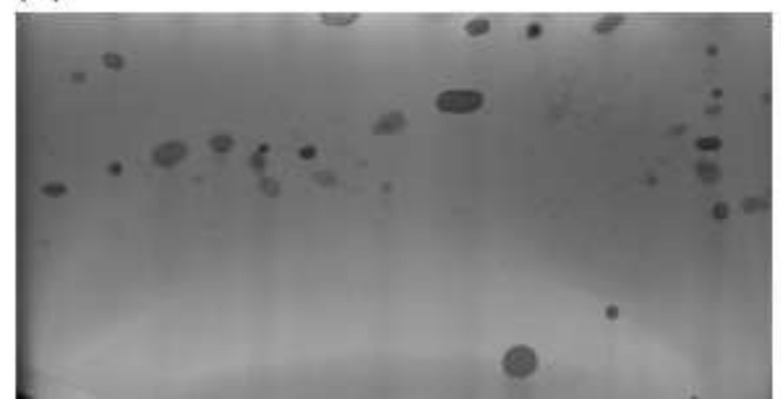

(b)

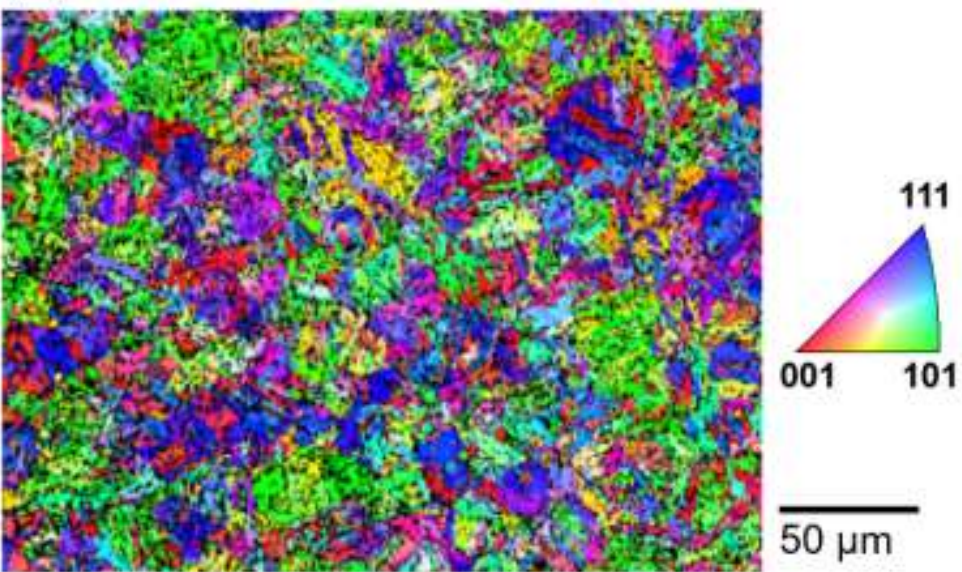

(d)

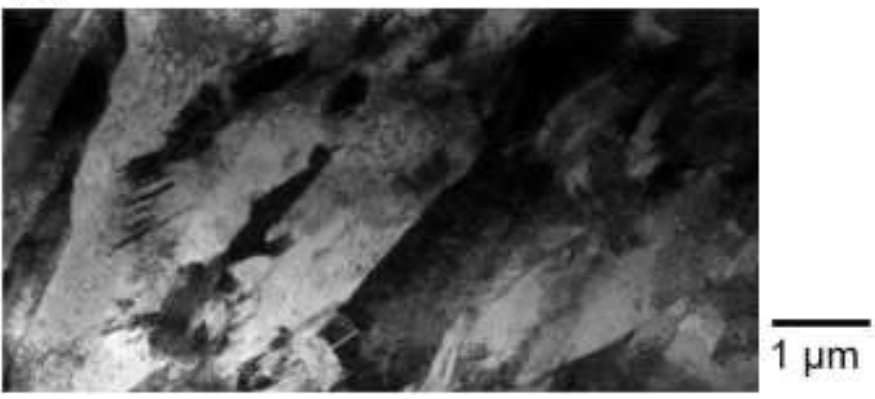

Figure 1. Inverse pole figure (IPF) maps of 1020 steel (a) as-received and (b) after flash processing at $1125^{\circ} \mathrm{C}$ conditions. All the maps are acquired from the through thickness cross-section parallel to the rolling direction. Low magnification bright field-STEM images of (c) as-received and (d) after flash processing at $1125^{\circ} \mathrm{C}$ conditions. 
(a)

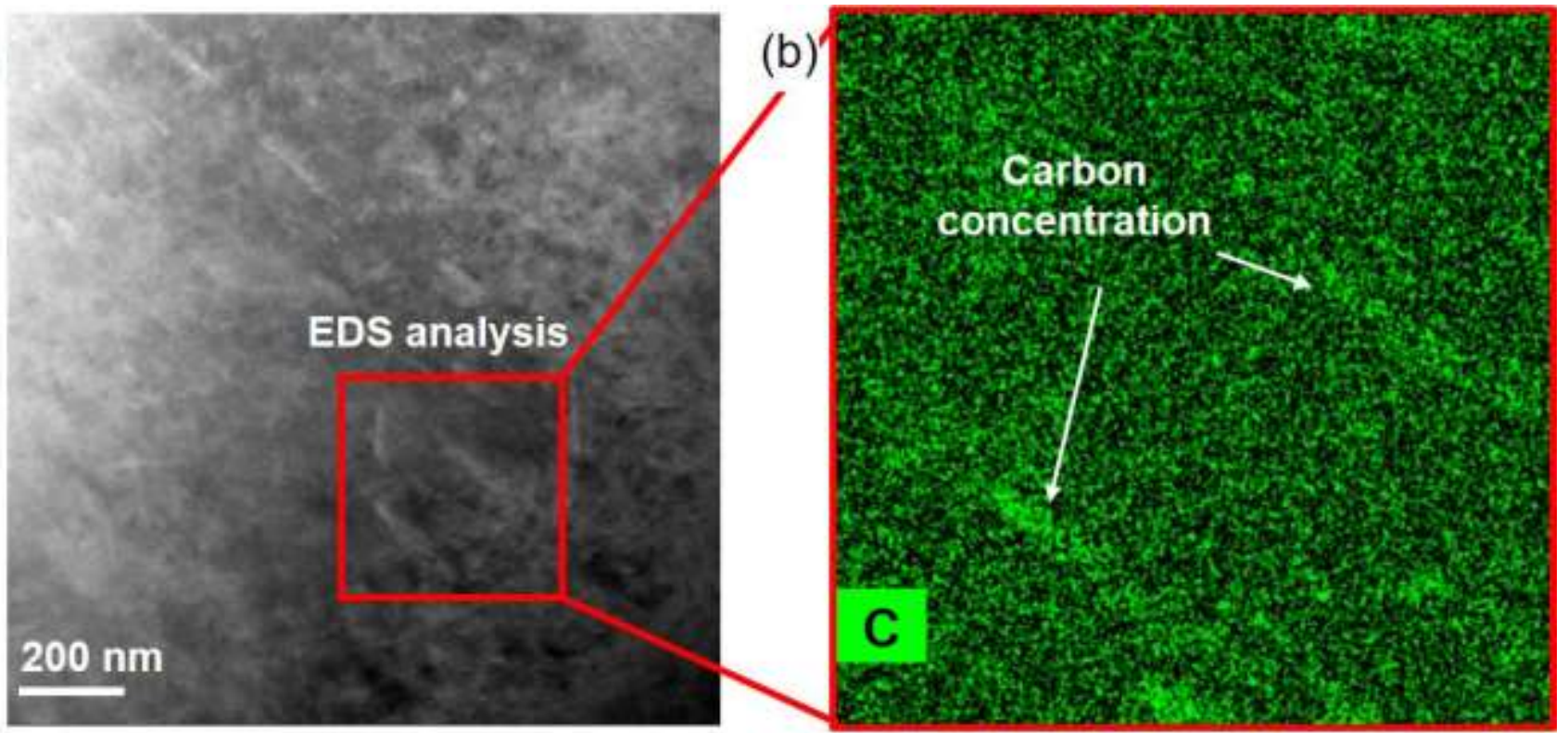

(c)

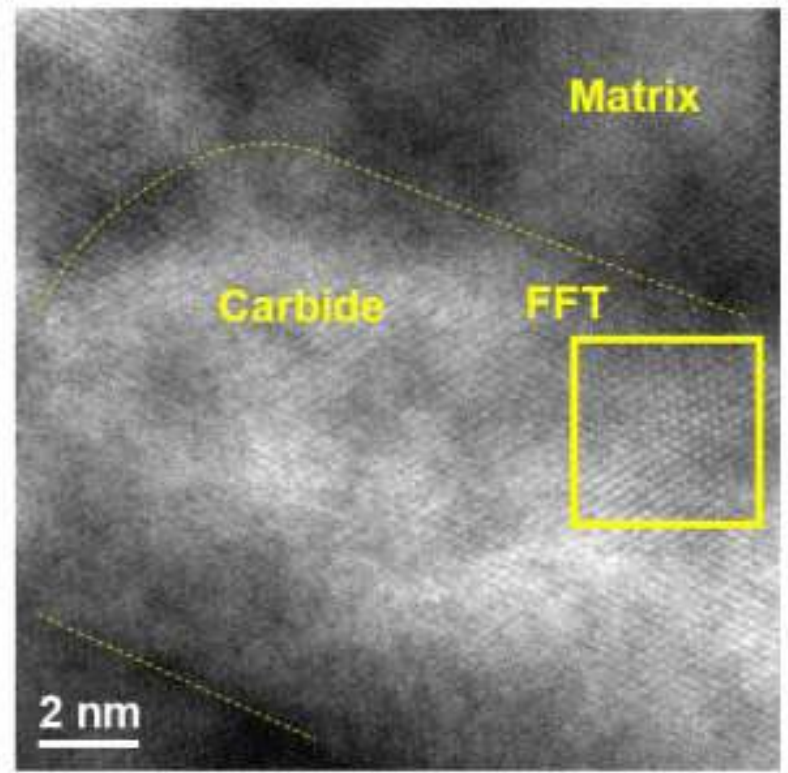

(d)

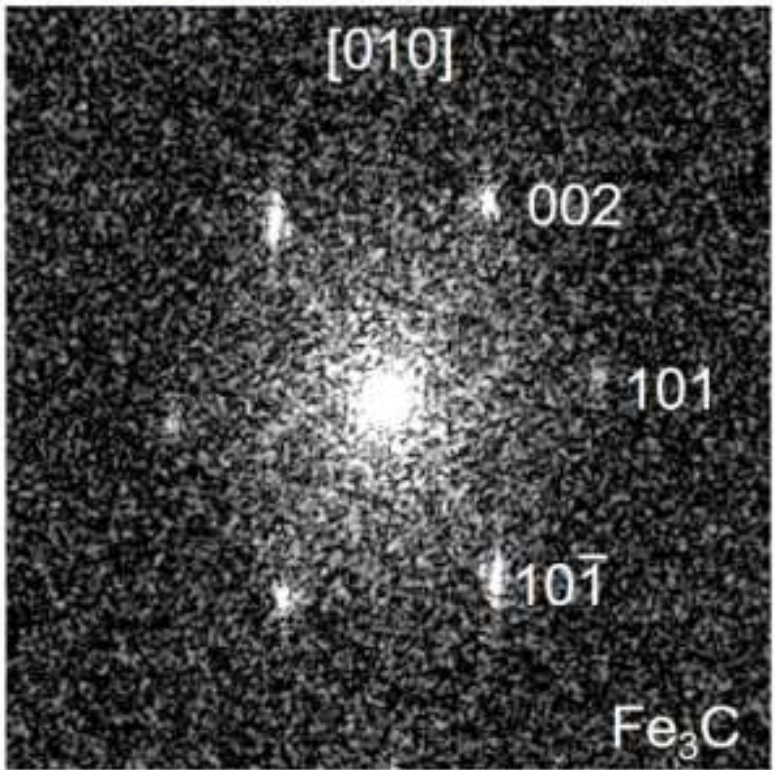

Figure 2. (a) HAADF-STEM image of ferrite grain of 1020 steel after flash processing at $1125{ }^{\circ} \mathrm{C}$ showing small laths. (b) STEM-EDS carbon map at the marked region in 2(a). (c) High-resolution HAADF-STEM image at the lath/matrix regions. (d) FFT pattern at the marked region in 2(c), indexed as the $\mathrm{Fe} 3 \mathrm{C}$ phase.

References

[1] B. Panigrahi, Bulletin of Mater. Sci. (2001), p. 361.

[2] T. Lolla, et al., Mater. Sci. Tech. 24 (2013), p. 863.

[3] I. Wood, et al., J. Applied Crystallography 37 (2004), p. 82.

[4] This research is sponsored by the US Department of Energy, Advanced Manufacturing Office, under Contract DE-AC05-00OR22725 with UT-Battelle, LLC. Microscopy conducted using instruments that are part of ORNL Center for Nanophase Materials Sciences and Nuclear Science User Facilities, which are U.S. DOE Office of Science User Facilities. 